\title{
Structural response to non-stationary thunderstorm outflows: Multi-variate vs equivalent mono-variate simulation
}

\author{
Giovanni Solari $^{\mathrm{a} *}$, Patrizia De Gaetano ${ }^{\mathrm{b}}$ \\ ${ }^{a}$ Department of Civil, Chemical and Environmental Engineering, Polytechnic School, \\ University of Genoa, Genoa, Italy, *corresponding author, giovanni.solari@unige.it \\ ${ }^{b}$ ARPAL - Regional Agency for the Protection of the Liguria Environment, Genoa, Italy
}

\begin{abstract}
The European Projects "Wind and Ports" and "Wind, Ports and Sea" gave rise to an extensive wind monitoring network in the High Tyrrhenian Sea area, from which many records of thunderstorm outflows were extracted. Initially, they were analysed to inspect their statistical properties. Later on, a hybrid multi-variate strategy for simulating the non-stationary wind field of the thunderstorm outflows was formulated and implemented to determine the time-domain response of structures. This paper shows the conceptual and numeric simplifications involved by embedding the equivalent wind spectrum technique, a method developed in a stationary framework, within the above non-stationary formulation. It leads to generate a multi-variate non-stationary wind field through the simulation of a mono-variate stationary process, without any relevant loss of precision.
\end{abstract}

Keywords: Numerical simulation, Stochastic dynamics, Time-domain analysis, Thunderstorm outflow.

\section{Introduction}

The study of thunderstorm outflows and their loading of structures is a dominant topic of modern wind engineering [1,2]. Thunderstorms are mesoscale atmospheric phenomena that consist of a set of cells that evolve in about 30 minutes over a few kilometres on the horizontal [3]. They give rise to intense transient downdrafts that impact the earth's surface followed by radial outflows with a typical "nose" profile $[4,5]$ and horizontal ring vortices. The ensemble of these air movements is called "downburst" (Figure 1) and is divided into macro-burst and micro-burst depending on whether its size is greater or smaller than $4 \mathrm{~km}$ [3]. The design wind velocity is often related to intense micro-bursts.

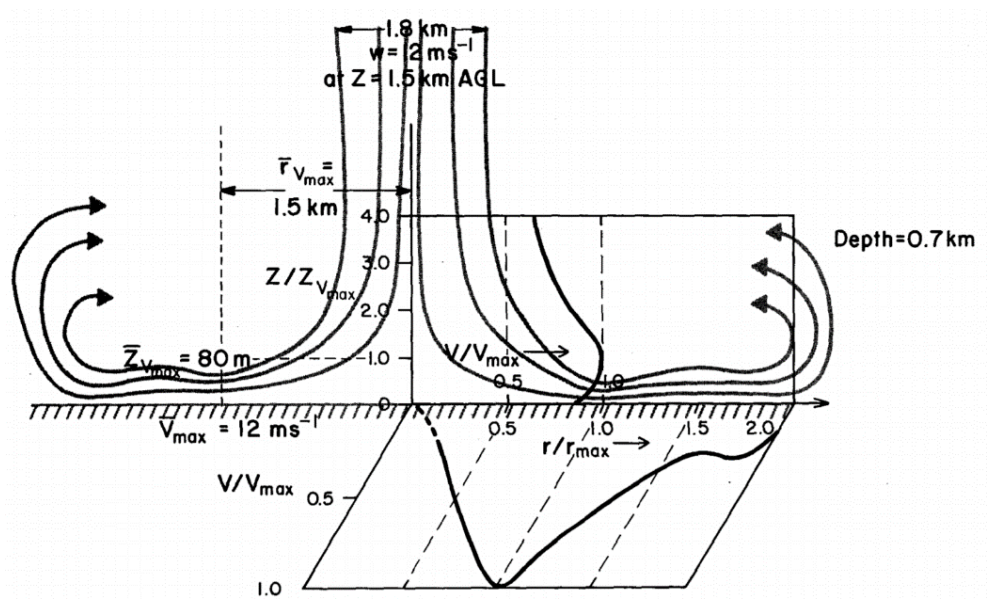

Fig. 1: Thunderstorm downburst and nose velocity profile in the radial outflow [5]. 
The literature is rich in contributions aiming to determine the dynamic response of reference systems to thunderstorm outflows. It exhibits an extensive panorama of procedures whose complexity matches the complexity of these phenomena [6-12]. Many other papers did not reach the evaluation of the windinduced response, but provided propaedeutic methods to represent transient wind fields in the timedomain [13-15]. A dominant aspect of most of these contributions is the striking contrast between the formulation of refined procedures and the poorness of the experimental data used to support theory.

The European Projects "Wind and Ports" [16] and "Wind, Ports and Sea" [17] offer a unique chance to formulate methods robustly coherent with real data. In this framework, an extensive wind monitoring network was created in the High Tyrrhenian area, from which many records of thunderstorm outflows were gathered [18]. Such records were analysed first aiming to evaluate their statistical properties [19, 20], then to develop criteria to determine the loading and response of structures. First, the response spectrum technique was generalised from the seismic field to thunderstorm outflows [21, 22]. Then, a hybrid strategy aiming to simulate transient wind velocity fields of thunderstorm outflows was developed and time-domain integrations of the response of slender vertical structures were carried out [23].

This paper focus on the conceptual and numerical simplifications involved by embedding the equivalent wind spectrum technique (EWST) [24, 25] within the above non-stationary formulation. It leads to generate a multi-variate non-stationary wind field through the simulation of a mono-variate stationary process, without any relevant loss of precision [26]. This property is proved through analytical derivations and applicative examples to structure test cases.

\section{Structure test cases}

Three real slender vertical structures are examined here as reference test cases: a steel lighting pole, a steel telecommunication antenna mast and a reinforced concrete telecommunication tower already studied in [23, 26]. For each of these structures, Figure 2 shows a picture, the model scheme, and the first 3 modal shapes $\psi_{1}, \psi_{2}, \Psi_{3}$. Table 1 reports the main properties: $H$ is the total height; $n_{1}, n_{2}, n_{3}$ are the first 3 natural frequencies; $\xi$ is the structural damping coefficient; $N$ is the number of nodes of the structural model. More details are provided in [23].

(a)

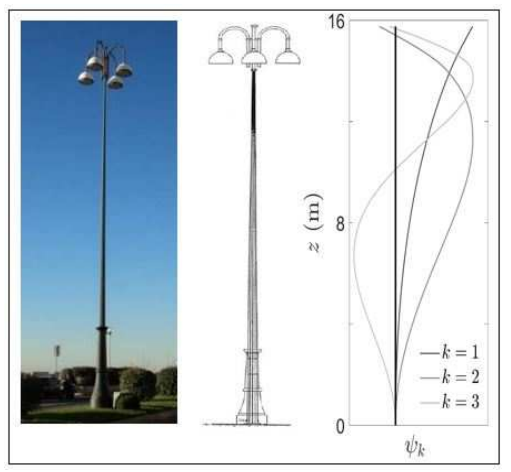

(b)
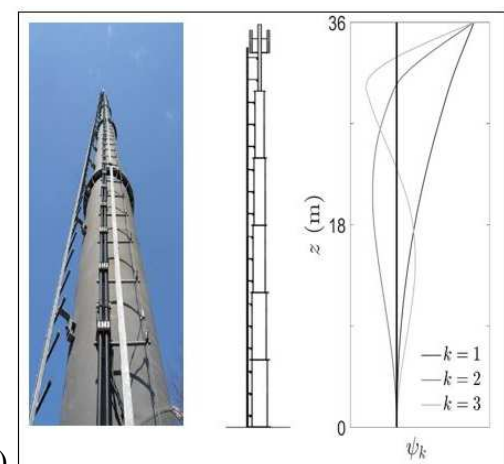

(c)

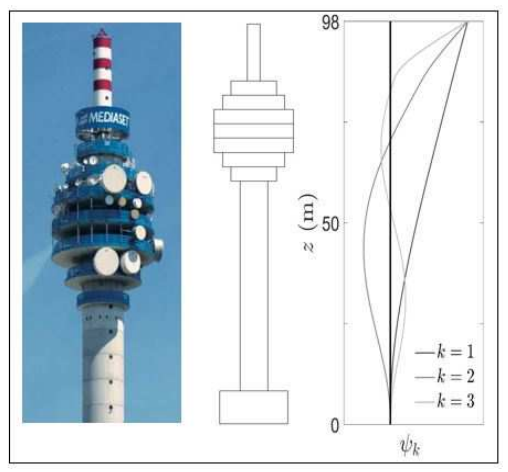

Fig. 2. Structure test cases [23]: a) steel lighting pole (S1); b) steel telecommunication antenna mast (S2); c) reinforced concrete telecommunication tower (S3).

Table 1. Main properties of the three structure test cases.

\begin{tabular}{llcccccc}
\hline Structure & Description & $H(\mathrm{~m})$ & $n_{1}(\mathrm{~Hz})$ & $n_{2}(\mathrm{~Hz})$ & $n_{3}(\mathrm{~Hz})$ & $\xi$ & $N$ \\
\hline S1 & Steel lighting pole & 15.76 & 0.532 & 3.186 & 8.744 & 0.01 & 16 \\
S2 & Steel telecommunication antenna mast & 36.00 & 0.821 & 3.106 & 5.972 & 0.01 & 19 \\
S3 & R.C. telecommunication tower & 98.00 & 0.494 & 3.167 & 6.274 & 0.02 & 26 \\
\hline
\end{tabular}




\section{Wind velocity model}

The horizontal component of the wind velocity in a thunderstorm outflow (Fig. 1) along a vertical axis is expressed here by the classical decomposition rule $[27,28]$ :

$$
\begin{aligned}
& v(z, t)=\bar{v}(z, t)+v^{\prime}(z, t) \\
& v^{\prime}(z, t)=\sigma_{v}(z, t) \tilde{v}^{\prime}(z, t)
\end{aligned}
$$

where $z$ is the height above ground, $t \in[0, \Delta T]$ is the time, $\Delta T=10$ minutes, $\bar{v}$ is the slowly-varying mean wind velocity, $v^{\prime}$ is the residual fluctuation, $\sigma_{v}$ is the slowly-varying standard deviation of $v^{\prime}$, $\tilde{v}^{\prime}$ is the reduced turbulent fluctuation dealt with as a stationary Gaussian random field with zero mean and unit standard deviation. The extraction of $\bar{v}$ from $v$ and of $\sigma_{v}$ from $v^{\prime}$ is carried out here by a moving average filter with a moving average period $T=30$ s [19]. Replacing Eq. (2) into Eq. (1):

$$
v(z, t)=\bar{v}(z, t)\left[1+I_{v}(z, t) \tilde{v}^{\prime}(z, t)\right]
$$

where $I_{v}$ is the slowly-varying turbulence intensity:

$$
I_{v}(z, t)=\frac{\sigma_{v}(z, t)}{\bar{v}(z, t)}
$$

The decoupling of space and time in $\bar{v}$ and $I_{v}$ allows us to express these two quantities as:

$$
\begin{aligned}
& \bar{v}(z, t)=\bar{v}_{\text {max }}(h) \alpha(z) \gamma(t) \\
& I_{v}(z, t)=\bar{I}_{v}(h) \beta(z) \mu(t)
\end{aligned}
$$

where $\bar{v}_{\max }$ is the maximum value of $\bar{v}$ in $\Delta T ; h$ is a reference height; $\alpha$ is a non-dimensional function of $z$ that defines the shape of the vertical profile of $\bar{v}$ [29-31], being $\alpha(h)=1 ; \gamma$ is a nondimensional function of $t$ that expresses the time variation of $\bar{v}$, being $\gamma_{\max }=1$. Similarly, $\bar{I}_{v}$ is the average value of $I_{v}$ in $\Delta T ; \beta$ is a non-dimensional function of $z$ that defines the shape of the vertical profile of $\bar{I}_{v}$, being $\beta(h)=1 ; \mu$ is a non-dimensional function of $t$ that expresses the time variation of $I_{v}$, being $\bar{\mu}=1$.

The reduced turbulent fluctuation $\tilde{v}$ is identified by its cross-power spectral density (CPSD) expressed here by the classical models usually adopted for synoptic winds [32].

Replacing Eqs. (5) and (6) into Eq. (3):

$$
v(z, t)=\bar{v}_{\max }(h) \alpha(z) \gamma(t)\left[1+\bar{I}_{v}(h) \beta(z) \mu(t) \tilde{v}^{\prime}(z, t)\right]
$$




\section{Hybrid simulation}

Diversely from classical Monte Carlo simulations of non-stationary vector fields [33-36], the hybrid strategy proposed in [23] to generate artificial velocity fields of thunderstorm outflows is based on simulating one at a time and then assembling the different ingredients that make up the wind velocity model in Eq. (8). A brief description of each step is given below.

Step 1: Velocity scale. The maximum value of $\bar{v}$ at height $h$ is evaluated by extreme statistics [37] as a function of the return period. In this paper, $\bar{v}_{\max }(h)=36.5 \mathrm{~m} / \mathrm{s}$, being $h=13 \mathrm{~m}$.

Step 2: Vertical profiles. The vertical profiles of $\bar{v}$ and $I_{v}$ are evaluated by assigning $\alpha(z)$ and $\beta(z)$ through expressions coherent with measures. In this paper $\alpha(z)$ is provided by the model proposed in [19] for $J=4$ values of the height $z_{m}$ at which $\bar{v}$ is maximum, $z_{m}=25,50,75,100 \mathrm{~m} ; \beta(z)=1$ [19].

Step 3: Slowly-varying time dependence. The random time-dependence of $\bar{v}$ and $I_{v}$ is simulated by gathering measured thunderstorm outflow records [19] and extracting from them synchronous pairs of $\gamma(t)$ and $\mu(t)$ sample functions. In this paper $K=93$ records are used.

Step 4: Turbulence field. The space-time variation of the stationary Gaussian field $\tilde{v}^{\prime}$ is simulated by a Monte Carlo algorithm [38] based on the spectral representation [39, 40]. Its computational efficiency is increased by replacing harmonic superimposition by a Fast Fourier Transform based implementation [41] and by factorizing the PSD matrix of $\tilde{v}^{\prime}$ by its POD eigenvalues and eigenvectors [42, 43]. The PSD and the coherence function of $\tilde{v}$ are expressed by [32]:

$$
\begin{aligned}
& S_{\tilde{v}^{\prime}}(z, n)=\frac{6.868 L_{v}(z) / \bar{v}_{\text {max }}(z)}{\left[1+10.302 n L_{v}(z) / \bar{v}_{\text {max }}(z)\right]^{5 / 3}} \\
& \operatorname{Coh}_{\tilde{v}^{\prime} \tilde{v}^{\prime}}\left(z, z^{\prime}, n\right)=\exp \left\{-\frac{2 n c_{z}\left|z-z^{\prime}\right|}{\bar{v}_{\max }(z)+\bar{v}_{\text {max }}\left(z^{\prime}\right)}\right\}
\end{aligned}
$$

where $L_{v}(z)=34.6 \mathrm{~m}$ [19] and $c_{z}=10$ is the exponential decay coefficient of $\tilde{v}^{\prime}$ [32]. Coherently with measurements, simulations are carried out with a time step $\Delta t=0.1 \mathrm{~s}$ in a time interval $\Delta T=10$ minutes. The turbulence harmonic content is simulated between 0 and the cut-off frequency $n_{c}=5 \mathrm{~Hz}$, with a frequency resolution $\Delta n=1 / 600 \mathrm{~Hz} . L=1,000$ artificial wind fields of $\tilde{v}$ are simulated for each $J=4$ velocity profiles.

Step 5: Component assemblage. $M=J \times K \times L=4 \times 93 \times 1,000=372,000$ thunderstorm velocity fields are simulated for each of the 3 test structures examined. Since they are discretized by $N=16,19,26$ joints (Table 1), all in all 22,692,000 artificial velocity histories are generated. Figure 3 shows three sample functions of a wind velocity field with $z_{m}=50 \mathrm{~m}$.

The performance of the whole simulation algorithm was discussed in [23], where it was shown that the hybrid technique is endowed with limited errors and produces wind fields adhering to measured data. 
(a)
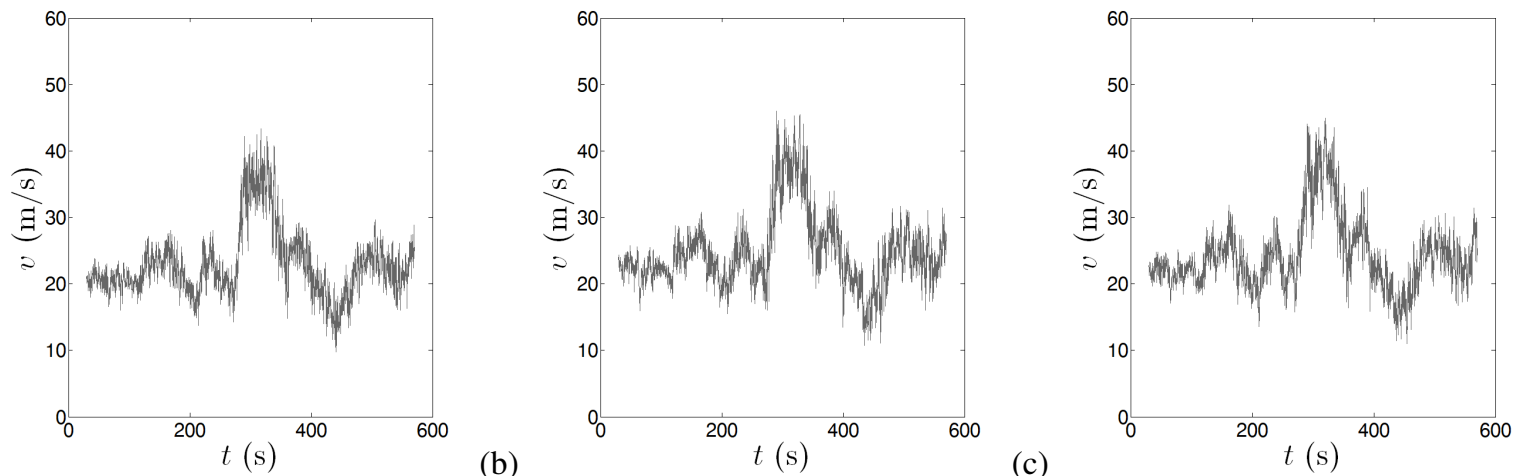

Fig. 3. Sample functions of a wind velocity field $v\left(z_{m}=50 \mathrm{~m}\right)$ at: a) $z=18 \mathrm{~m}$; b) $z=54 \mathrm{~m}$; c) $z=80 \mathrm{~m}$.

\section{Equivalent hybrid simulation}

The EWST introduced in [24] and refined in [25] for slender structures is a method that replaces the actual turbulent field, as a random function of time and space, by an equivalent turbulent fluctuation, as a random function of time, identically coherent in space. The generalization of EWST to transient thunderstorm outflows was introduced in [22]. Accordingly, the reduced equivalent turbulent fluctuation $\tilde{v}_{e q}^{\prime}$ is defined by its PSD:

$$
S_{\tilde{v}^{\prime}, e q}(n, \delta)=S_{\tilde{v}^{\prime}}\left(z_{e q}, n\right) C(\delta n)
$$

where $S_{\tilde{v}}$ is the PSD of $\tilde{v}^{\prime}, z_{e q}=0.6 H$ is the equivalent height, $C$ is the frequency filter:

$$
C(\eta)=\frac{1}{\eta}-\frac{1}{2 \eta^{2}}\left(1-e^{-2 \eta}\right) \quad(\eta>0) \quad ; \quad C(0)=1
$$

$\eta$ is the argument of $C ; \delta$ is the size factor:

$$
\delta=\frac{\kappa c_{z} H}{\bar{v}_{\max }\left(z_{e q}\right)}
$$

$\kappa$ is the modal shape factor. Dealing with slender vertical cantilever structures, whose first mode shape may be approximated as $\psi_{1}(z)=(z / H)^{\zeta}, \quad \kappa=0.5 /(\zeta+1)^{0.55}$ [25]:

Using this method Eq. (7) may be approximated by the relationship:

$$
v(z, t)=\bar{v}_{\max }(h) \alpha(z) \gamma(t)\left[1+\bar{I}_{v}(h) \beta(z) \mu(t) \tilde{v}_{e q}^{\prime}(t, \delta)\right]
$$

Figure 4 shows three sample functions of the equivalent velocity field corresponding to the actual field in Figure $3\left(z_{m}=50 \mathrm{~m}\right)$. The shape and the trend of the diagrams in Figure 3 are preserved while the high frequency harmonic content is filtered out to take into account, in equivalent terms, the coherence of the fluctuations and the aerodynamic admittance. 


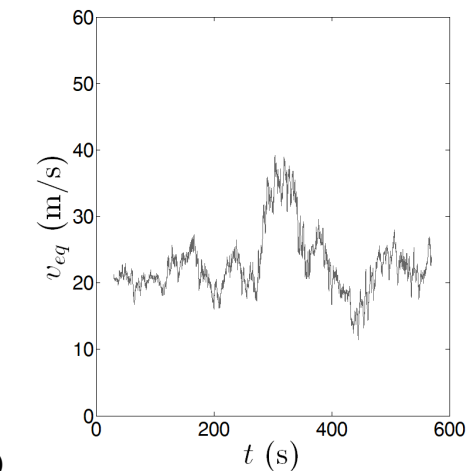

(a)
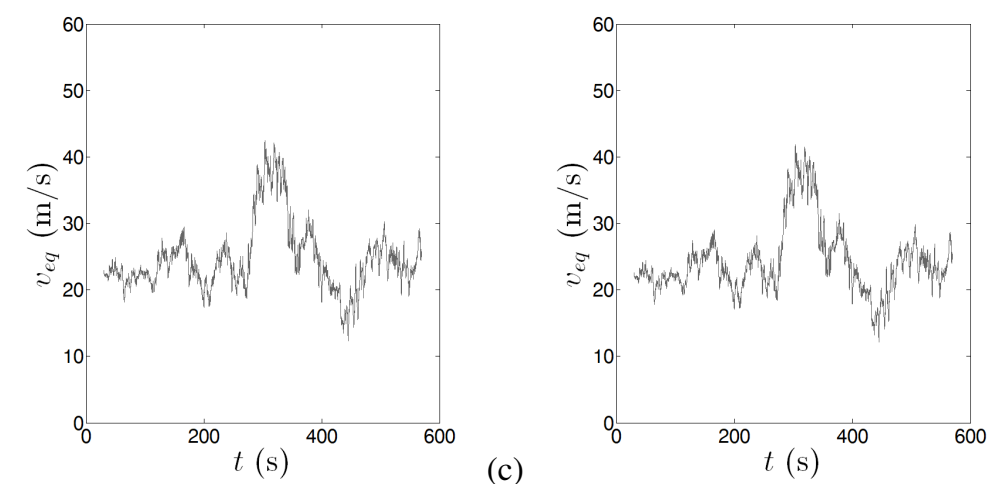

Fig. 4. Sample functions of the equivalent velocity field $v_{e q}$ corresponding to that in Fig. $4\left(z_{m}=50 \mathrm{~m}\right)$ : (a) $z=18 \mathrm{~m}$; (b) $z=$ $54 \mathrm{~m}$; (c) $z=80 \mathrm{~m}$.

Eq. 13 does not modify the slowly-varying mean part of $v$ whereas it drastically changes its residual fluctuation by replacing the 2-D process $\tilde{v}^{\prime}(z, t)$ by the equivalent 1-D process $\tilde{v}_{e q}^{\prime}(t, \delta)$. The step from Eq. (7) to Eq. (13) is a formidable simplification whose correctness was proved conceptually in [26] by stressing that, though used in the non-stationary field, the EWST is strictly applied to the sole stationary part of the turbulent fluctuations.

\section{Wind-excited response}

Let us consider a slender vertical structure with linear elastic behaviour. Using modal analysis, assuming that natural frequencies are well-separated and dealing with damping as small and proportional, its wind-excited response is given by:

$$
x(z, t)=\sum_{k} \psi_{k}(z) p_{k}(t)
$$

where $\psi_{k}$ is the $k$-th mode shape and $p_{k}$ is the $k$-th principal coordinate:

$$
\ddot{p}_{k}(t)+2 \xi\left(2 \pi n_{k}\right) \dot{p}_{k}(t)+\left(2 \pi n_{k}\right)^{2} p_{k}(t)=\frac{1}{m_{k}} f_{k}(t)
$$

$m_{k}$ and $f_{k}$ being the $k$-th modal mass and modal force, respectively:

$$
\begin{aligned}
& m_{k}=\int_{0}^{H} m(z) \psi_{k}^{2}(z) d z \\
& f_{k}(t)=\int_{0}^{H} f(z, t) \psi_{k}(z) d z
\end{aligned}
$$

in which $m$ is the structural mass per unit length and $f$ is the aerodynamic wind loading:

$$
f(z, t)=\frac{1}{2} \rho v^{2}(z, t) b(z) c_{D}(z)
$$

$\rho$ is air density, $v$ is the wind velocity defined by Eq. (7) or (13), $b$ is the reference size of the structure 
cross-section, $c_{D}$ is the drag coefficient evaluated neglecting the transient character of the wind field [44].

The integration of the equations of motion is performed in the state space by introducing a Hamming windowing at the beginning of the wind loading history to avoid initial transient effects. Each time step $\Delta t=0.1 \mathrm{~s}$ is divided into 10 parts and a linear interpolation of the wind loading is applied. Analyses are carried out by neglecting aerodynamic damping and retaining the contribution of the sole first mode.

Figure 5 and 6 show the first modal force and the first modal displacement of structure S3 for the simulated thunderstorm outflows in Figure 3 and 4. Despite the first is obtained by Eq. (7) whereas the second derives from the simplified Eq. (13), the similarity between corresponding diagrams is apparent.

(a)
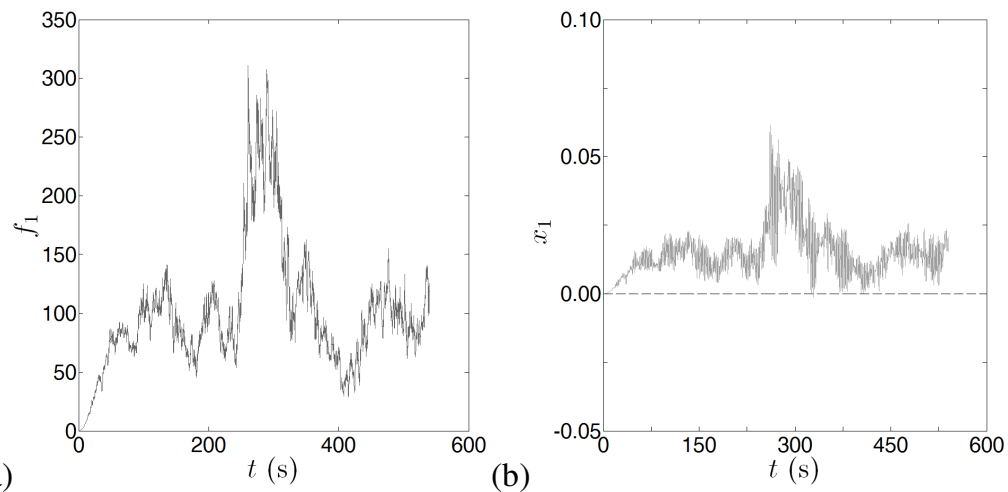

Fig. 5. First modal force $f_{1}$ (a) and first modal displacements $x_{1}$ (b) of structure $\mathrm{S} 3$ for the simulated thunderstorm outflow in Fig. 3.
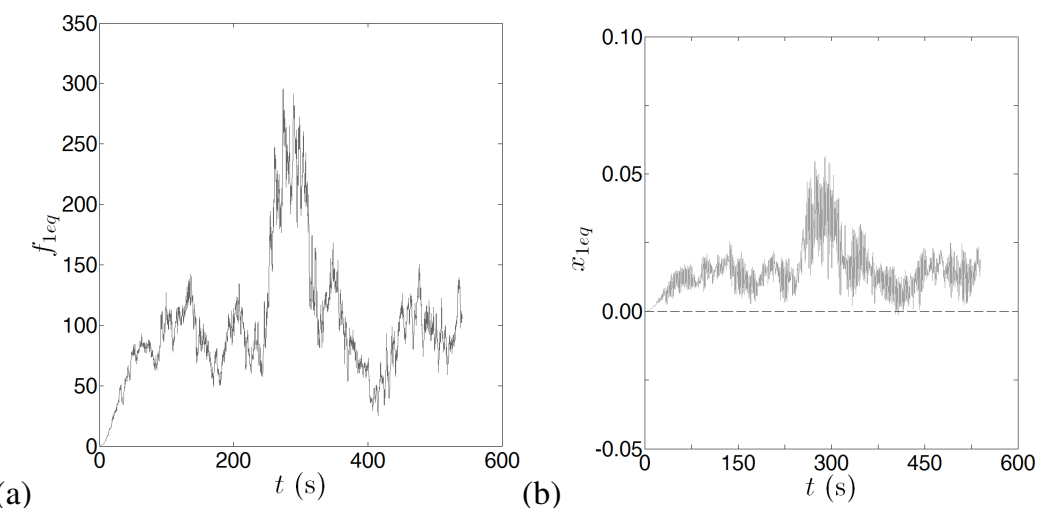

Fig. 6. Equivalent first modal force $f_{1}$ (a) and first modal displacements $x_{1}$ (b) of structure S3 for a thunderstorm outflow simulated by EWST (Fig. 4).

To check the global efficiency of the equivalent hybrid simulation, 93,000 values of the maximum displacement at the top of each structure are evaluated for the 4 wind velocity profiles considered here. Thus, all in all, $93,000 \times 3 \times 4=1,116,000$ values of $x_{\max }(H)$ are extracted and analysed probabilistically. Tables 2 and 3 summarize the mean values and the cov of $x_{\max }(H)$ evaluated, respectively, by the hybrid simulation of Eq. (7) and by the equivalent hybrid simulation of the approximate Eq. (13). The values in parenthesis are the percent errors committed (with reference to Tables 2) by EWST. Despite the complexity of the problem dealt with, the error never exceeds $4 \%$. In particular, it is almost 
surprising the precision with which the EWST replicates not only the mean of $x_{\max }(H)$ but also its cov.

Table 2. Mean value $(\mathrm{m})$ and cov of the maximum displacement $x_{\max }$ at the structure top $H$ by time-domain analysis.

\begin{tabular}{lcccccccc}
\hline Structure & \multicolumn{4}{c}{$\left\langle x_{\max }(H)\right\rangle$} & \multicolumn{3}{c}{$\operatorname{cov}\left(x_{\max }(H)\right)$} \\
\cline { 2 - 8 } & $z_{m}=25 \mathrm{~m}$ & $z_{m}=50 \mathrm{~m}$ & $z_{m}=75 \mathrm{~m}$ & $z_{m}=100 \mathrm{~m}$ & $z_{m}=25 \mathrm{~m}$ & $z_{m}=50 \mathrm{~m}$ & $z_{m}=75 \mathrm{~m}$ & $z_{m}=100 \mathrm{~m}$ \\
\hline S1 & 0.651 & 0.651 & 0.643 & 0.639 & 0.242 & 0.246 & 0.241 & 0.240 \\
S2 & 0.326 & 0.357 & 0.364 & 0.370 & 0.216 & 0.218 & 0.218 & 0.218 \\
S3 & 0.046 & 0.072 & 0.082 & 0.087 & 0.184 & 0.192 & 0.195 & 0.193 \\
\hline
\end{tabular}

Table 3. Mean value (m) and cov of the maximum displacement $x_{\max }$ at the structure top $H$ by equivalent time-domain analysis (in parenthesis the percent error with reference to Table 2).

\begin{tabular}{lcccccccc}
\hline Structure & \multicolumn{4}{c}{$\left\langle x_{\max }(H)\right\rangle$} \\
\cline { 2 - 9 } & $z_{m}=25 \mathrm{~m}$ & $z_{m}=50 \mathrm{~m}$ & $z_{m}=75 \mathrm{~m}$ & $z_{m}=100 \mathrm{~m}$ & $z_{m}=25 \mathrm{~m}$ & $z_{m}=50 \mathrm{~m}$ & $z_{m}=75 \mathrm{~m}$ & $z_{m}=100 \mathrm{~m}$ \\
\hline S1 & $0.670(+3)$ & $0.665(+2)$ & $0.658(+2)$ & $0.654(+2)$ & $0.247(+2)$ & $0.249(+1)$ & $0.244(+1)$ & $0.243(+1)$ \\
S2 & $0.335(+3)$ & $0.362(+1)$ & $0.374(+3)$ & $0.377(+2)$ & $0.221(+2)$ & $0.219(+1)$ & $0.223(+2)$ & $0.220(+1)$ \\
S3 & $0.046(-1)$ & $0.070(-3)$ & $0.079(-4)$ & $0.084(-4)$ & $0.180(-2)$ & $0.185(-4)$ & $0.188(-4)$ & $0.186(-4)$ \\
\hline
\end{tabular}

\section{Conclusions}

This paper deals with the dynamic response of structures to thunderstorm outflows in the time-domain. Diversely from classical Monte Carlo methods that simulate a generic non-stationary vector field by a unitary generation procedure, the hybrid simulation adopted here generates an artificial velocity field of a thunderstorm outflow by simulating one at a time and then assembling the different ingredients that make up the target wind velocity model. In addition, the simulation of the reduced turbulent fluctuation, which is basically a stationary Gaussian random field, is traced back to an equivalent mono-variate process by making recourse to the equivalent wind spectrum technique. This approach, called equivalent hybrid simulation, makes it possible to generate a multi-variate non-stationary wind field through the simulation of a mono-variate stationary process. The comparison between the two methods proves that this solution involves a huge reduction of the computational time without any relevant loss of precision.

\section{Acknowledgements}

This research is funded by the European Research Council (ERC) under the European Union's Horizon 2020 research and innovation program (grant agreement No. 741273) for the project THUNDERR Detection, simulation, modelling and loading of thunderstorm outflows to design wind-safer and costefficient structures - supported by an Advanced Grant 2016. The data exploited have been recorded by the monitoring network realized for the European Projects "Winds and Ports" (grant No. B87E09000000007) and "Wind, Ports and Sea" (grant No. B82F13000100005), funded by the European Territorial Cooperation Objective, Cross-border program Italy-France Maritime 2007-2013.

\section{References}

[1] C.W. Letchford, C. Mans, M.T. Chay, Thunderstorms - their importance in wind engineering (a case for the next generation wind tunnel), J. Wind Eng. Ind. Aerod. 90 (2002) 1415-1433.

[2] G. Solari, Emerging issues and new scenarios for wind loading on structures in mixed climates, Wind Struct. 19 (2014) 295-320. 
[3] T.T. Fujita, Downburst: meteorological features and wind field characteristics, J. Wind Eng. Ind. Aerod. 36 (1990) 75-86.

[4] R.G. Goff, Vertical structure of thunderstorm outflows, Mon. Wea. Rev. 104 (1976) 1429-1440.

[5] M.R. Hjelmfelt, Structure and life cycle of microburst outflows observed in Colorado, J. Appl. Meteorol. 27 (1988) 900-927.

[6] E.C.C. Choi, F.A. Hidayat, Dynamic response of structures to thunderstorm winds, Prog. Struct. Eng. Mat. 4 (2002) 408-416.

[7] L. Chen, C.W. Letchford, Parametric study on the alongwind response of the CAARC building to downbursts in the time domain, J. Wind Eng. Ind. Aerod. 92 (2004) 703-724.

[8] M.T. Chay, F. Albermani, B. Wilson, Numerical and analytical simulation of downburst wind loads, Eng. Struct. 28 (2006) 240-254.

[9] X. Chen, Analysis of alongwind tall building response to transient nonstationary winds, J. Struct. Eng. ASCE 134 (2008) 782-791.

[10] D.K. Kwon, A. Kareem, Gust-front factor: new framework for wind load effects on structures, J. Struct. Eng. ASCE 135 (2009) 717-732.

[11] T.H. Le, L. Caracoglia, Reduced-order wavelet-Galerkin solution for the coupled, nonlinear stochastic response of slender buildings in transient winds, J. Sound Vibr. 344 (2015) 179-208.

[12] T.H. Le, L. Caracoglia, Computer-based model for the transient dynamics of a tall building during digitally simulated Andrews AFB thunderstorm, Comp. Struct. 193 (2018) 44-72.

[13] L. Wang, M. McCullough, A. Kareem, A data-driven approach for simulation of full-scale downburst wind speeds, J. Wind Eng. Ind. Aerod. 123 (2013) 171-190.

[14] G. Huang, H. Zheng, Y.L. Xu, Y. Li, Spectrum models for non-stationary extreme winds, J. Struct. Eng. ASCE 141 (2015) 04015010.

[15] L. Peng, G. Huang, X. Chen, A. Kareem, Simulation of multivariate nonstationary random processes: hybrid stochastic wave and proper orthogonal decomposition approach, J. Eng. Mech. ASCE 143 (2017) 04017064.

[16] G. Solari, M.P. Repetto, M. Burlando, P. De Gaetano, M. Pizzo, M. Tizzi, M. Parodi, The wind forecast for safety and management of port areas. J. Wind Eng. Ind. Aerod. 104-106 (2012) 266277.

[17] M.P. Repetto, M. Burlando, G. Solari, P. De Gaetano, M. Pizzo, M. Tizzi, A GIS-based platform for the risk assessment of structures and infrastructures exposed to wind, Adv. Eng. Softw. 117 (2018) 29-45.

[18] P. De Gaetano, M.P. Repetto, T. Repetto, G. Solari, Separation and classification of extreme wind events from anemometric records, J. Wind Eng. Ind. Aerod. 126 (2014) 132-143.

[19] G. Solari, M. Burlando, P. De Gaetano, M.P. Repetto, Characteristics of thunderstorms relevant to the wind loading of structures, Wind Struct. 20 (2015) 763-791.

[20] S. Zhang, G. Solari, P. De Gaetano, M. Burlando, M.P. Repetto, A refined analysis of thunderstorm outflow characteristics relevant to the wind loading of structures, Prob. Eng. Mech. 54 (2018) 924.

[21] G. Solari, P. De Gaetano, M.P. Repetto, Thunderstorm response spectrum: fundamentals and case study, J. Wind Eng. Ind. Aerod. 143 (2015) 62-77.

[22] G. Solari, Thunderstorm response spectrum technique: theory and applications, Eng. Struct. 108 (2016) 28-46. 
[23] G. Solari, D. Rainisio, P. De Gaetano, Hybrid simulation of thunderstorm outflows and windexcited response of structures, Meccanica 52 (2017) 3197-3220.

[24] G. Solari, Equivalent wind spectrum technique: theory and applications, J. Struct. Eng. ASCE 114 (1988) 1303-1323.

[25] G. Piccardo, G. Solari, Generalized equivalent spectrum technique, Wind Struct. 1 (1998) 161-174.

[26] G. Solari, P. De Gaetano, Dynamic response of structures to thunderstorm outflows: response spectrum technique vs time-domain analysis, Eng. Struct. 176 (2018) 188-207.

[27] L. Chen, C.W. Letchford, A deterministic-stochastic hybrid model of downbursts and its impact on a cantilevered structure, Eng. Struct. 26 (2004) 619-629.

[28] J.D. Holmes, H.M. Hangan, J.L. Schroeder, C.W. Letchford, K.D. Orwig, A forensic study of the Lubbock-Reese downdraft of 2002, Wind Struct. 11 (2008) 19-39.

[29] R.M. Oseguera, R.L. Bowles, A simple analytic 3-dimensional downburst model based on boundary layer stagnation flow, NASA Technical Memorandum 100632, 1988.

[30] D.D. Vicroy, Assessment of micro burst models for downdraft estimation, J. Aircraft. 29 (1992) 1043-1048.

[31] G.S. Wood, K.C.S. Kwok, An empirically derived estimate for the mean velocity profile of a thunderstorm downburst, Proceedings of the 7th Australian Wind Engineering Society Workshop, Auckland, Australia, 1998.

[32] G. Solari, G. Piccardo, Probabilistic 3-D turbulence modeling for gust buffeting of structures, Prob. Eng. Mech. 16 (2001) 73-86.

[33] Y. Li, A. Kareem, Simulation of multivariate nonstationary random processes by FFT, J. Eng. Mech. ASCE 117 (1991) 1037-1058.

[34] G. Deodatis, Non-stationary stochastic vector processes: seismic ground motion applications, Prob. Eng. Mech. 11 (1996) 149-168.

[35] S. Sakamoto, R. Ghanem, Simulation of multi-dimensional non-Gaussian non-stationary random fields, Prob. Eng. Mech. 17 (2002) 167-176.

[36] G. Huang, An efficient simulation approach for multivariate nonstationary process: Hybrid of wavelet and spectral representation method, Prob. Eng. Mech. 37 (2014) 74-83.

[37] S. Zhang, G. Solari, Q. Yang, M.P. Repetto, Extreme wind speed distribution in a mixed wind climate, J. Wind Eng. Ind. Aerod. 176 (2018) 239-253.

[38] L. Carassale, G. Solari, Monte Carlo simulation of wind velocity fields on complex structures, J. Wind Eng. Ind. Aerod. 94 (2006) 323-339.

[39] M. Shinozuka, C.M. Jan, Digital simulation of random processes and its applications, J. Sound Vibr. 25 (1972) 111-128.

[40] Y. Li, A. Kareem, Stochastic decomposition and application to probabilistic mechanics, J. Eng. Mech. ASCE 121 (1995) 162-174.

[41] J.N. Yang, On the normality and accuracy of simulated random processes, J. Sound Vibr. 26 (1973) 417-428.

[42] M. Di Paola, Digital simulation of wind field velocity, J. Wind Eng. Ind. Aerod. 74-76 (1998) 91109.

[43] L. Carassale, G. Solari, F. Tubino, Proper Orthogonal Decomposition in wind engineering. Part 2: Theoretical aspects and some applications, Wind Struct. 10 (2007) 177-208.

[44] CNR-DT 207/2008, Instructions for assessing wind actions and effects on structures, National Research Council, Rome, Italy, 2009. 